\title{
Why We Need Dedicated Web-based Collaboration Platforms for Inter-organizational Connectivity? A Research Synthesis
}

\author{
Atia Bano Memon \\ Department of Computer Science at the University of Leipzig, Leipzig, Germany \\ E-mail: memon@informatik.uni-leipzig.de \\ Kyrill Meyer \\ Institute for Applied Informatics at the University of Leipzig, Leipzig, Germany \\ E-mail: meyer@informatik.uni-leipzig.de
}

Received: 18 May 2017; Accepted: 27 July 2017; Published: 08 November 2017

\begin{abstract}
This paper examines the potential of existing web-based collaboration services in supporting the interorganizational connectivity throughout the collaboration process. In doing so, the paper initially presents a brief overview and a hierarchical classification with respect to the degree and complexity of service integration of existing collaboration services which are applicable in inter-organizational settings. Successively, their shortcomings in supporting the process of interorganizational collaboration are herein determined and discussed. As a conclusion, the paper elucidates the rational and need for designing the dedicated web-based collaboration platforms for facilitating the interorganizational connectivity within a particular business sector.
\end{abstract}

Index Terms -Web-based collaboration, Digital communication technologies, Online B2B connectivity, Collaboration tools, Inter-organizational collaboration.

\section{INTRODUCTION}

With the increased degree of business competition at the global levels, it has gradually become essential for the business organizations to collaborate with other organizations, customers, institutions, and even with the competitors [32, 51] in order to combine different knowledge and assets [22] that are not covered by the organization itself. As a result, organizations are continuously seeking the complementary expertise and resources across the organizational, industrial (disciplinary), and geographical boundaries. Since the inter-organizational collaboration (abr. IOC) brings several benefits to the participating organizations such as the access to complementary assets [14], knowledge exchange and the creation of new knowledge [16, 39], and sharing of associated costs [15], it is increasingly considered valuable by almost every organization [46-48]. However, it is a complex and critical activity that needs to be carefully planned and executed in order to be successful and truly fruitful for the participating organizations, and thus demands intertwined processes of analyzing organization's needs and wants, searching and selecting the sources of complementary assets, partnering, and managing long-term relations. Moreover, screening and monitoring the technological environment and selecting the prospective business partners is not an easy task for the organizations [31]; in particular for the Small and Medium sized Enterprises (SMEs) who are frequently equipped with limited information and financial resources [32, 51].

Consequently, for enabling the best possible value creation and engaging in fruitful co-operations, organizations require some sort of intermediating platforms that facilitate such a process by searching for and matching potential partners according to their goals, needs, and competencies, and subsequently enabling the undertaking of mutual activities between the selected partners in an efficient and effective manner. Traditionally, these tasks had been performed by the intermediary organizations who are variously recognized as third parties, brokers, or agents of information exchange [13, 45], technology transfer [17], or network formation [5] between two or more firms. Whilst there is a substantial evidence of the effectiveness and benefits of intermediary organizations in IOC process, the need for more advanced and efficient platforms for bilateral and multilateral collaboration originates from two factors. Firstly, the potential of innovation intermediaries to aggregate and exchange partnering information is somewhat restricted by the geographic limitations of their reach which hinders their capacities to facilitate the IOC in an international context. Secondly, beyond facilitating the co-operation (acquisition and exchange of partnering information) intermediaries offer very little support to the connected organizations in interacting and undertaking collaborative activities with each other.

In this esteem, the mechanism of web-based communication brings a potential solution by enabling 
the organizations to interact with each other across the globe in a similar way as in physical spaces. Web-based communication, also referred to as online/electronic/ digital communication, has been the feature of the internet since its earliest days when it started out as a giant bulletin board system allowing the users to exchange software, data, messages, and news with each other in a seamless manner across the geographic borders. The concept of web-based interaction is not synonymous with the internet but is the most prominent part of the internet that can be defined as a techno-social system enabling the human interaction - human cognition, communication, and co-operation [10] - based on technological networks [2]. With the almost ubiquitous world telecommunication networks combined with the information structuring and storing capabilities of computers, the new wave of web-based human interaction has completely dissolved the geographic borders and thus transformed the world into a global sphere wherein the people can interact with each other in a similar way as they communicate in physical spaces despite of being miles apart. As a result, the notion of communicating over the web has increasingly become pervasive and part of everyday life. The practices and supporting technologies have been continually evolving since their origin and currently there exist a myriad of such technologies that depending on the type and complexity of the offered functionality are commonly referred to as either communication or collaboration tools. Nevertheless, since the communication is also a part of the collaboration process, in this paper we broadly refer to all such tools that support any sort of human interaction (communication, coordination, or collaboration) as web-based collaboration tools (abr. WBCTs).

Increasingly, the application of WBCTs has not only altered the practices of interpersonal interaction, but has spanned across the intra- and inter-organizational connectivity as well. By offering several easy and efficient mechanisms of sharing the knowledge and ideas, the paradigm has drastically changed the way the organizations collaborate and exchange information with their customers, other organizations, and the society. In this context, this paper examines the potential of existing WBCTs in supporting the inter-organizational connectivity throughout the collaboration process. In pursuance of this, initially a succinct overview and classification of the existing WBCTs which are applicable in inter-organizational settings is presented. Subsequently, their inadequacies in supporting the IOC process are herein identified and discussed. As a conclusion, the paper provides a preliminary brainstorming about a research agenda and an invitation to the web developers and researchers to formally debate, investigate and report on the requirements, design, and development of the dedicated web-based technological artifacts for supporting the inter-organizational connectivity throughout the IOC process within a particular business sector.

The remainder of the paper is organized as follows. In section 2, we discuss the previous related work and present the rationale of undertaking this study. Section 3 depicts the methodological orientation. The hierarchical classification of WBCTs applicable in the IOC settings and their challenges in supporting the IOC throughout the process are presented in section 4 and 5, respectively. The paper concludes in section 6 with an outlook to future research.

\section{RELATED WORK}

Given the prevalence of WBCTs and their potential to support the human interaction in a wide array of contexts, scholars have been investigating their role from different perspectives since many years. Nevertheless, the extant scholarship concerning the WBCTs has mainly been focusing on their application and effectiveness in the individual and community settings. Many scholars have focused on their benefits in facilitating the interpersonal communication (e.g. [27]) and thereby explored that how such tools enable the creation of online communities whereby the community members can exchange information and interact with each other in a similar way as in physically located communities. The other group of scholars have focused on the benefits of WBCTs in enhancing a certain phenomenon (e.g. communication in education/learning environments [29, 50] and dissemination of tourism information [56]), or solving a certain societal challenge (e.g. disaster management [26]).

Among the studies focusing on the application of WBCTs in the organizational context, scholars are documenting their implications mainly with respect to three dimensions:

i. Knowledge sharing: the generation, integration, sharing and dissemination of organizational knowledge (e.g. [6, 43]), and reaching out at global audience and thereby gaining promotional advantages and cutting marketing expenses (e.g. [1]),

ii. Coordination and teamwork: improving the information flow between the employees and thus facilitating the mutual learning inside the organization (e.g. [24]), and soliciting market demands and engaging customers in the cocreation process (e.g. [42]),

iii. Organizational benefits: facilitating ecommerce (buying-selling) activities (e.g. [3]), or achieving specific organizational goals (e.g. stock exchange market forecasting [8]).

Surprisingly, a little attention has been previously paid to the application of WBCTs in supporting the interorganizational communication, interconnection, and goal achievement. Among the existing studies, most of them are focusing on the features and incentives of a specific type of tools and thereby describe how such tools may facilitate the undertaking of particular collaboration activities. For instance, Ref. [54] has discussed how the conversational technologies (e.g. email, discussion 
forums, and web-conferencing tools) in general and wiki in particular can be used to facilitate the management (creation, acquisition, publishing, and sharing) of organizational knowledge generated by a group of individuals through dialog with questions and answers. Similarly, Ref. [52] has described that how the different existing WBCTs are helpful in supporting the different stages of group decision making process (intelligence, design, choice, and implementation) and thereby proposed a fit-viability model for selecting a particular tool for supporting the specific activities of decision making among distributed work teams.

Increasingly, the other scholars have focused on the impacts of existing WBCTs towards the particular collaboration activities. For example, Ref. [40] has explored the effects of using collaboration technologies towards the management of collaborative projects wherein the business partners residing in different geographic locations are involved. The authors have determined several aspects of coordination, communication, and adaptation to distributed work environments that influence the success of virtual teams. Likewise, Ref. [30] has explored how the collaboration personas can be used to design the collaboration technologies for mediating the group communication and team interaction in business contexts. The collaboration personas are targeted to capture the linkages, collective goals, and collaboration aspects of the groups, and thus guide the development of new collaboration tools that better meet the needs of typical groups. Accordingly, the literature on the WBCTs in the context of IOC is somehow segmented and lacking a conclusive description of their application, capacities, benefits and/or inadequacies in supporting the IOC throughout the process (i.e. from the inception to the completion of a particular collaboration alliance).

\section{Methodological RemarKs}

The work discussed in this paper is leaning around the Design Science Research (abr. DSR) methodology for Information Systems proposed by [36]. The DSR aligning with the fields of engineering and 'the science of the artificial' [44] relates with the creation of IT artifacts that are the innovations embodied by the ideas, practices, products, or technical capabilities helping to solve reallife problems effectively [18, 44]. DSR is contrasted from the social/behavioral science paradigm that has been dominating the information systems research for a long time in a way that 'the behavioral science strives to understand what is true', whereas 'the DSR seeks to create what is effective' [18]. DSR artifacts include both purely (or nearly purely) technical and socio-technical artifacts [53].

The development of DSR artifacts requires a schematic procedure in order to ensure the novelty and utility of constructed artifacts and thus develop the effective solutions of hitherto unsolved problems. According to [36], the creation of DSR artifacts involves six key activities: problem identification, solution design, development, demonstration, evaluation, and communication (cf. Fig. 1). The entry point in the process depends on the intention of creating a particular artifact which might be to solve a problem (problem centered initiation), achieve an objective (objective centered initiation), implement a required functionality (design and development centered), or fulfill a client's requirement (client/context centered initiation). In this paper, we take an early step towards creating a sociotechnical artifact aiming to support the IOC process by employing a problem centered approach. The scope of this paper is to investigate the state of the art of existing WBCTs and thereby define and motivate the problem statement.

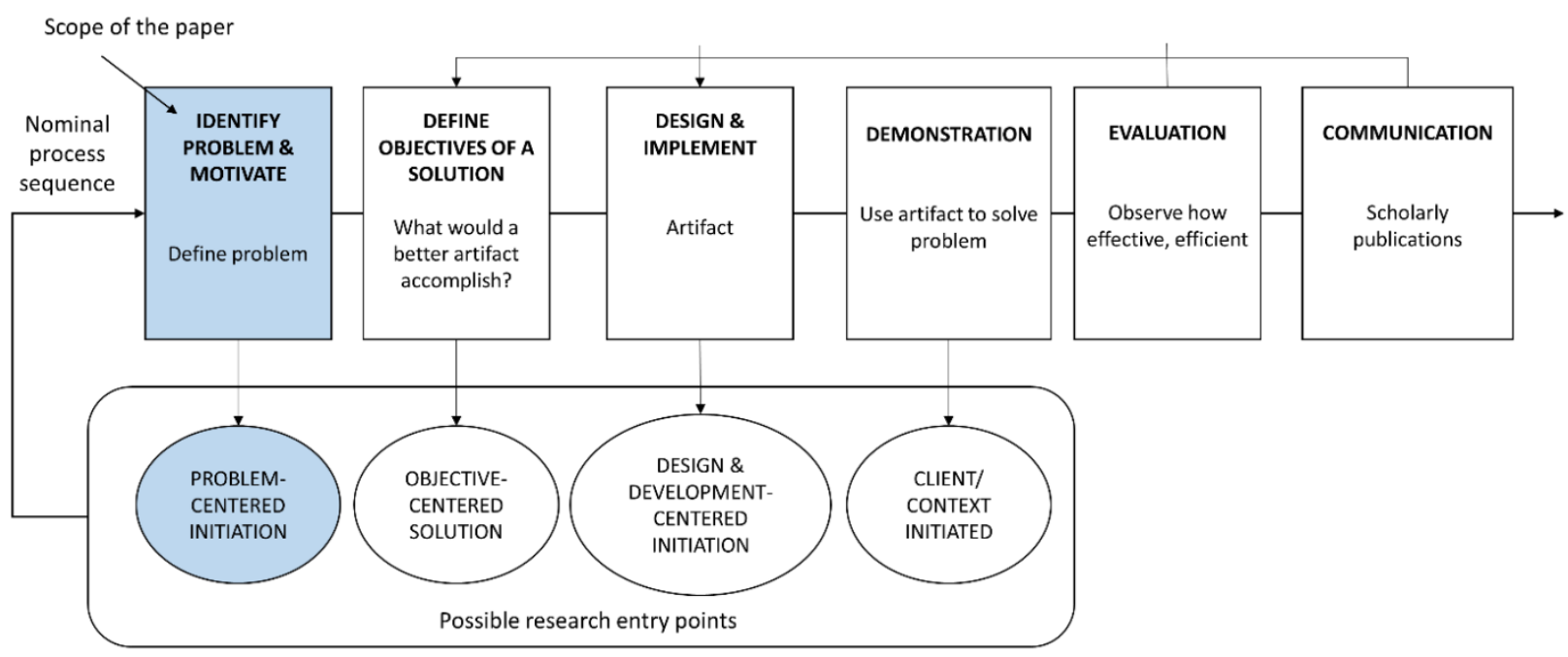

Fig.1. Design science research approach [18] and scope of the paper 


\section{WEB-BASED COLLABORATION TOOLS FOR INTER- ORGANIZATIONAL CONNECTIVITY}

As a result of the continuous advancements and developments of web-based technologies since their inception, currently there exist a myriad of WBCTs which are commonly delineated as web 1.0 or web 2.0 tools depending on the web incarnation that they are based on. The web 1.0 (also known as read-only web) refers to the first implementation of the web that served as a web of information connections, or a web of cognition/ percipience [35] allowing the people to search for and read the information with a very little user interaction or content contribution. Accordingly, the web 1.0 based collaboration tools mainly support simple content delivery from one participant to the other. For the businesses, web 1.0 tools introduced a new mechanism of disseminating somewhat mono-directional information. They could provide online catalogues or brochures similar to the advertisements in newspapers and magazines in order to present their productions that the other people could read [2].

The web 2.0 (also known as read-write web) refers to the second generation of the web that was created to advance the read-only web into 'The web as a platform' [34] whereby the content and applications instead of being generated and published by individuals are created and continually modified by all the interested users in a participatory and collaborative fashion [25]. The users thus become the actors consuming as well as producing and publishing different types of digital content at the same time [20]. For the businesses, web 2.0 tools facilitate the direct, effective and timely communication between the producers and consumers of business products and services.

Taking all together, the existing WBCTs offer a wide variety of interaction support ranging from information exchange to the coordination and collaboration of the teams. Nevertheless, they all focus on supporting a set of particular activities of human interaction and thus remarkably differ from each other with respect to the degree (the number) as well as the complexity (the interconnectivity and mutual dependency) of their integrated services. For example, whereas the basic communication tools such as email services or instant messengers facilitate the human interaction in a relatively simpler way (asynchronous communication), the advanced communication media such as web conferencing suites and social networking sites enable many methods of human interaction (textual, verbal and visual communication) with a possibility of using more than one at a time. The more advanced services such as project management tools take it even further by combining the communication abilities with the task coordination and project management facilities. Accordingly, we classify the existing WBCTs into five broad classes in an increasing order of the degree and complexity of their offered services: communication, conversation, content sharing, coordination, and community tools (see Fig. 2). It is necessary to note that while there exist other WBCTs that may not completely fit into any of these categories and thereby may form new categories (e.g. online games, virtual world, etc.), the study concentrates only on the media applicable in the context of inter-organizational connectivity.

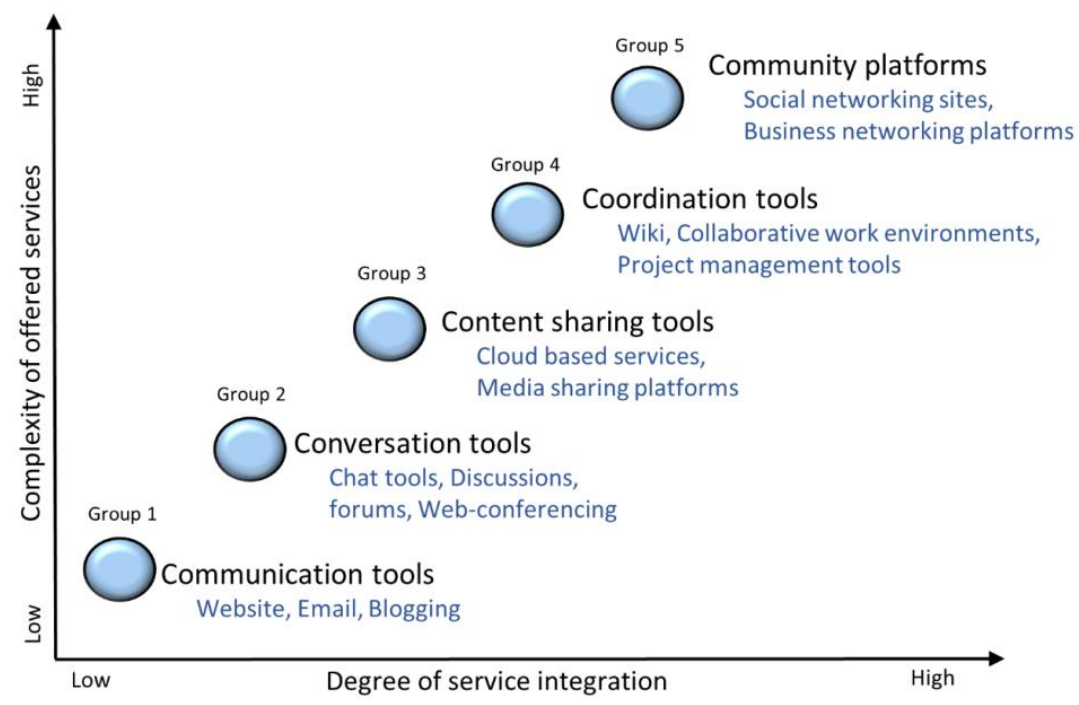

Fig.2. Hierarchical classification of existing WBCTs applicable in the IOC context

\section{A. Communication Tools}

The web-based communication tools are the simplest and earliest of WBCTs that allow the users to exchange somewhat unidirectional information at a time. The basic communication media available today include the two traditional technologies of web 1.0 (website and email) and a web 2.0 based technology (weblogs).

Website: A website which is a collection of interrelated web pages usually served from a single web domain is the foremost communication channel available for and adapted by business organizations. They use websites for establishing an online presence and sharing their 
information with a wider audience. Generally, websites support the sharing of static and unidirectional information, however, the ecommerce websites may also include a shopping cart facility and online transactions support to alleviate the geographical restrictions of a brick-and-mortar business style [12].

Email: An email (short for electronic mail) service (e.g. Outlook ${ }^{1}$, and $\mathrm{Gmail}^{2}$ ) is the best known asynchronous communication tool for exchanging digital messages from one-to-one or one-to-many recipients. It offers several intuitive features such as forwarding messages, creating mailing groups, attaching documents, and sorting messages automatically in a chronologically order.

Weblog: A weblog (shortened as blog) is a simple content management tool enabling the people to build easily updatable web diaries or online journals [23]). The weblog entries (aka weblog posts) are made in journal style and are usually displayed in reverse chronological order [41]. Weblogs are created for multiple purposes ranging from the personal diaries which are meant for family and friends to the personal knowledge repositories which are maintained by the professionals, learning journals or networking instruments [4]. The organizational weblogs can be private (internal to an organization) or publicly accessible containing the text, photographs, videos, or audio clips [2, 35]. Weblogs offer two interesting features. One, a weblog post can be linked to other weblog posts so that the interesting posts are tied together facilitating the people with similar interests to build relationships and form communities. Second, the weblog readers can syndicate (subscribe to) a weblog using the RSS (short for Really Simple Syndication or Rich Site Summary) technology that automatically checks the weblog feeds and provides updates in XML based web feed format [23] summarizing the information items and links to the information sources [33].

\section{B. Conversation Tools}

The web-based conversational tools extend the concept of traditional in-person discussions to the online space by enabling the users to engage in real-time conversations involving the textual as well as audio/video messages. Such tools range from the simple instant messengers to the discussion forums and complete web-conferencing suites.

Messenger: An instant messaging or chat software such as Yahoo messenger ${ }^{3}$ allows the users to share short messages in an asynchronous mode. Such tools usually use split screens for displaying the user messages whereby the conversation history is always stored unless the user deliberately deletes it. Besides supporting the text chat, few services also extend to the higher fidelity experiences enabling the users to also share the video links. Increasingly, the instant messaging services may also be structured within the chat rooms that support the multicasting and whereby the usernames, number of

\footnotetext{
https://outlook.live.com/

2 https://www.google.com/gmail/

${ }^{3}$ https://messenger.yahoo.com/
}

participating people, and discussion topic are always shown at the users' end.

Discussion Forum: A discussion forum (aka a bulletin board, discussion board, and discussion group) allows the people with common interests to debate and share certain information, questions, comments and opinions. The discussion posts are stored and sorted chronologically to form a discussion thread or topic. From a technological standpoint, forums or boards can be regarded as web applications managing user-generated content. They differ from chat rooms in that messages are often longer than one line of text, and are at least temporarily archived

Web-conferencing tools: A web conferencing tool such as Skype for business ${ }^{4}$ facilitates the real-time conversation involving text-based messages, voice and video among geographically dispersed participants. Such services may allow the real-time point to point communications as well as multicast communications from one sender to many receivers. Applications for web conferencing include peer-level online meetings, web seminars (webinars), and webcasts from a web-connected computer to other web-connected computers.

\section{Content sharing Tools}

The web-based content sharing tools enable the sharing of various types of user generated content in the centralized online spaces. The prominent examples of content sharing tools include the cloud-based sharing services, and media sharing platforms.

Cloud-based services: A cloud based sharing service facilitates the users to store the electronic documents in a shared online repository which can be accessed by anyone with appropriate permissions. With nearly ubiquitous internet connectivity these days, storing files remotely rather than locally boasts an array of advantages for the users including the wider accessibility, lower costs, improved security, easy syncing, sharing and collaboration, and more protection. Business organization build on cloud based file sharing in order to give their employees flexibility in file accessibility and reducing the costs of setting up virtual private networks and inpremise fileservers. Examples of well-known cloud based file sharing services include Dropbox ${ }^{5}$, Google Drive ${ }^{6}$, and OneDrive ${ }^{7}$ (formerly SkyDrive).

Media sharing platforms: A web-based media sharing platform refers to a social forum whereby the users interact with each other by sharing a variety of user generated content (often referred to as media object) via digital channels. Such platforms enable the users to upload the media to a central webserver that can be accessed from anywhere and are often equipped with a comment function enabling the discussion over the shared content whereby the users are usually allowed to control the access rights to the media they share. Another key feature of such platforms is the technique called 'embedding' that facilitates the cross-platform sharing or

\footnotetext{
${ }^{4}$ https://www.skype.com/en/business/skype-for-business/

${ }^{5}$ https://www.dropbox.com/

${ }^{6} \mathrm{https} / / / \mathrm{www}$.google.com/drive/

${ }^{7}$ https://onedrive.live.com/
} 
interlinking of the shared media by placing a short HTML snippet on the destination platform. Examples of such platforms include the YouTube ${ }^{8}$ that facilitates the sharing of videos, and SlideShare ${ }^{9}$ that enables the sharing of presentation slides.

\section{Coordination Tools}

The web-based coordination tools support the teamwork and attainment of common goals spanning across geographical boundaries by integrating the group members in a virtual working environment. Such tools range from the simple collaborative authoring tools such as Wiki to the collaborative document editing tools and the complex project management tools.

Wiki: Wiki (derived from the Hawaiian word wikiwiki meaning fast or quick) is a simple yet powerful webbased collaborative authoring tool [33]. The wiki process of co-construction of content is best known through the public collaborative encyclopedia - Wikipedia ${ }^{10}$. Wiki applications facilitate collaborative creation and editing of documents in real-time along with the revision mechanisms that support the monitoring [41] and rolling back of the changes [35]. Business organizations use wiki applications to keep track of internal procedures and knowledge by storing documents in a centralized knowledge repository and thus enabling the asynchronous contribution by a group of people, information annotation, efficient communication and productivity, harnessing of the power of diverse individuals to create collaborative works, and support for the content to evolve, expand, and improve incrementally over time [33].

Collaborative authoring tools: A collaborative document editing tool enables the users to collectively create and edit documents in real-time. Documents are stored in online repositories and thus can be shared, opened, and edited by multiple users simultaneously and users are able to see the changes that other collaborators make. Such applications may include a notification functionality prompting the users when a comment is made or replied to, a chat functionality allowing the collaborators to discuss the edits in real-time, and a revision history allowing the users to archive the additions made to the document. A widely used collaborative document editing tool is the Google Docs ${ }^{11}$ that facilitates the collaborative creation and editing of different types of text documents.

Project management tools: A project management tool, for example Basecamp ${ }^{12}$ or Trello ${ }^{13}$, facilitates the users to collaborate over a certain project covering all aspects of managing project from its genesis to its completion. The project management tools help to track complex projects distributed in many geographical places and/or managed by a number of project managers. Typical tasks

\footnotetext{
${ }^{8}$ https://www.youtube.com/

${ }^{9} \mathrm{http}: / / \mathrm{www}$. slideshare.net/

${ }^{10}$ https://www.wikipedia.org/

${ }^{11} \mathrm{https} / / / \mathrm{www} . g o o g l e . c o m /$ docs/about/

12 https://basecamp.com/

${ }^{13}$ https://trello.com/
}

supported by such tools include the project planning (mapping of project tasks and task interactions), task management (assignment, deadlines and status reports of tasks), document sharing and collaboration (central document repository accessible to project stakeholders), calendar and contact sharing (scheduled meetings, activity dates and automatically updating contacts), bug and error management (error reporting, viewing, notifying and updating for stakeholders), and time tracking (ability to track time for the tasks).

\section{E. Community Tools}

The community tools, commonly referred to as online community platforms (abr. OCPs), facilitate the building of online communities that can be defined as "aggregation of the individuals or business partners who interact around a shared interest, whereby the interaction is at least partially supported and/or mediated by technology and guided by some protocols or norms" [38]. In the course of business or professional organizations, the online community building brings a number of advantages including the self-disclosure, identity over the world, sharing of knowledge and the like. The paradigm of OCPs which arrived commercially about a decade ago has rapidly gained momentum over the recent years and currently there are tons of different networks available for individual as well as professional purposes. From the business perspective, OCPs can broadly be characterized as social networking sites which are open to a wide variety of users, and the networking platforms dedicated for the business organizations.

Social networking sites: A social networking site (abr. SNS) facilitates the creation and management of the connections with people based on similar interests or professions by constructing a public or semi-private profile within a bounded system [7]. Increasingly, the paradigm has provided many opportunities for intra- and inter-organizational connectivity that were previously not available or very difficult to acquire for most of the organizations on their own [21]. For example, the leading SNSs such as Facebook ${ }^{14}$, LinkedIn ${ }^{15}$, Google $+{ }^{16}$, and Xing ${ }^{17}$ offer the creation and hosting of the business pages (aka company pages) that enable the business organizations to introduce themselves, list and promote their products and/or services, post updates, advertise their events, solicit product reviews, interact directly with customers, and engage the user community in co-creation of innovative products and services.

Business networking platforms: A business networking platform enables the business organizations to create the business specific networks oriented around a particular theme, interest, or industry, and thereby facilitate the sharing of business specific content with the business professionals. Such platforms support business identity meaning the profiles are created with respect to the business specific information rather than the users'

\footnotetext{
${ }^{14}$ https://www.facebook.com/

${ }^{15} \mathrm{https} / / / \mathrm{www}$. linkedin.com/

${ }^{16} \mathrm{https} / / /$ plus.google.com/

${ }^{17}$ https://www.xing.com/
} 
biographical information. The business networking platforms may be oriented around a single business domain, or may support more than one business sector. In the latter case, the platforms usually enable the creation of smaller networks oriented around different themes. A prominent example of business specific networking platform is the British Connect ${ }^{18}$ platform.

\section{Challenges OF THE EXISTING WBCTS IN SUPPORTING THE IOC PROCESS}

The IOC process is a complex process progressing through different degrees of participant integration. In the literature on inter-organizational collaboration, several collaboration maturity models have been suggested such as Community linkage model [19], Peterson model [37], integration model [11], the seven-stage model [9], and the organizational integration rubric [55] each encompassing a different number of collaboration levels and differentiating them with respect to different dimensions and/or in a different context (see [9] for a review). For the purpose of current study, we select Community linkage model [19] as the most relevant framework. Ref. [19] arranges the extent of community based collaboration across five levels: networking, cooperation or alliance, coordination or partnership, coalition, and collaboration. Since the two higher levels (stages of coalition and collaboration) differentiate among themselves in terms of the structure and purpose of the participant integration while the mutual activities characterizing these stages remain identical, we condense them into a single stage of 'collaboration'. Accordingly, we build upon four key stages of collaboration process: communication/ networking (awareness of others' skills and competencies, and interaction with each other), cooperation (goal matching and mutual support to each other in achieving individual objectives), coordination/ partnering (undertaking of mutual projects with defined goals and responsibilities), and collaboration (long term relations characterized by mutual trust and interdependency). Whilst the existing WBCTs discussed in the preceding section offer great opportunities for supporting the various activities that are to be undertaken during the IOC process, their potential to support the entire IOC process in an effective and efficient manner is harnessed by the following challenges:

\section{A. Service Fragmentation and Issues of Information Integration}

Given that the existing WBCTs are oriented towards supporting varying kinds of interaction activities, a certain tool facilitates only a part of the IOC process (cf. Fig. 3). For example, whereas the communication and conversation tools enable the participating organizations to build awareness of and interact with each other, the coordination tools facilitate them in undertaking and managing the tasks over a certain project. As a result, all the required services that are needed for supporting IOC

\footnotetext{
${ }^{18}$ https://connect.innovateuk.org/
}

process remains scattered in different kinds of tools. Consequently, for addressing the particular requirements of different stages of the IOC process, an organization might need to exploit multiple tools in the course of a single collaboration. This turns the management of webbased collaborations a challenging and demanding task for the organizations as they have to familiarize themselves with the potentialities of all existing tools and select the appropriate tools every time they collaborate depending on the needs of a particular collaboration and/or preferences of involved parties.

Increasingly, even if the organizations invest substantial efforts in this process, there is an issue of information integration. For instance, if two organizations utilize the conversation tools for initial discussions, the collaborative work environments for simultaneous work on files, and project management tools for scheduling and tracking the project tasks; how can the resulting dispersed information be aggregated for the purpose of documentation and further reference during and after the completion of the project? No or limited availability of previously shared or collectively generated information at a central space on the one hand makes it difficult for the organizations to measure the success of their previous collaborations and thereby select the suitable partners for their future projects. On the other hand, it makes it challenging for the organizations to show their previous collaboration and success record in order to demonstrate their capabilities and attract new prospective partners.

\section{B. Service Diversity and Inadequate Collaboration Support}

The second challenge that the existing WBCTs encounter in supporting IOC process is the service diversity among the existing tools of a certain kind. For instance, when it comes to leveraging a community platform for communicating and cooperating with other partners, organizations find a number of community platforms available at their disposal. The existing platforms while focusing on a common goal of online community building differ across their scope as well as the service offerings. For example, whereas the Facebook platform offers a number of interaction options (public conversations by writing on each other's walls and commenting on public posts, and private communication through text messaging, and audio and video calls), the LinkedIn platform offers a limited set of services tailored in a professional manner such as exchanging emails, and sharing employees network. As a result of such diversity among different tools that facilitate a particular collaboration activity, the organizations have to explore and compare their features every time in order to choose the one that most addresses their needs and suits all the collaborators.

Additionally, there is also the scarcity of technological support for the advanced stages of the IOC process. As shown in Fig. 3, as the stages of IOC process progress towards the long-term collaboration, the support from the existing tools gradually diminishes. Interestingly, none of 
the existing WBCTs supports the organizations in recording their collaborating history, assessing team performance, and measuring the success of their previous collaborations in order to decide on with whom to align in long-term collaboration contracts. This elucidates that the existing WBCTs are oriented towards supporting human interaction in a general fashion and are therefore incapable of supporting the advanced stages of IOC process as supporting these stages requires a set of sophisticated and business-tailored services.

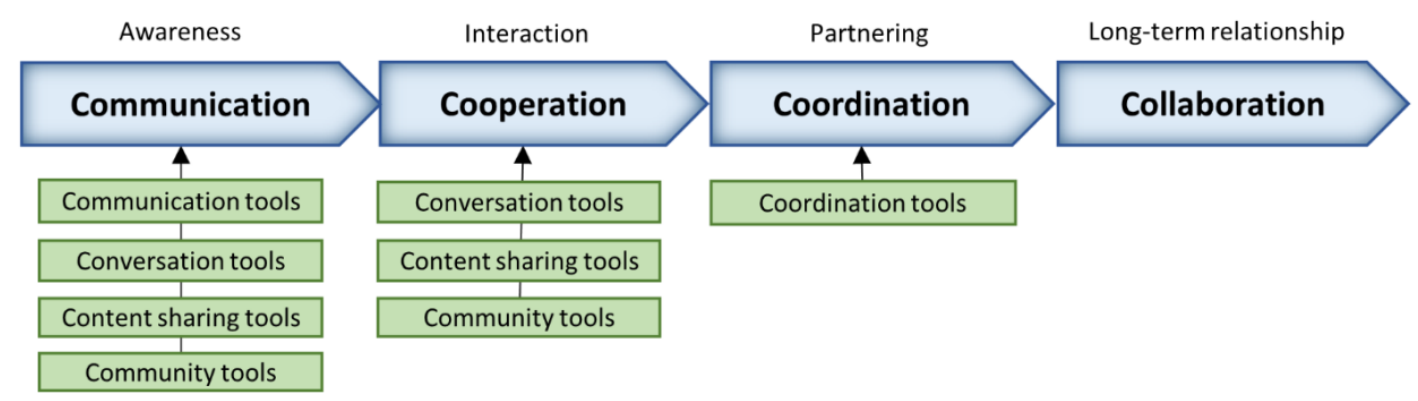

Fig.3. The exiting WBCTs supporting different stages of IOC process

\section{Lack of Domain Specificity and Dedicated Functionalities}

The third challenge of the existing WBCTs in supporting IOC process is the lack of support for domain specific features and dedicated functionalities. While there exist few WBCTs that differentiate between the interpersonal and organizational communications and thereby offer specific services for organizations, they do not consider the differences among the different types of organizations. For example, the SNSs offer separate and dedicated interaction services for the organizations in the form of business pages (aka company pages). Nevertheless, the business pages hosted on the existing SNSs are structured in a manufacturing firm style focusing on the marketing oriented services that are necessary for creating a buyer-seller relationship. Typical information fields appearing on business pages include basic information, organization category, contact details, and a listing of the products, services, and specialties. Whereas in the case of the organizations other than the manufacturing firms such as a science laboratory, or an education/research institute, there are no manufactured products or services offered for sale. Rather, there are a number of different pieces of domain specific information that need to be stated; especially when it comes to describing an organization for interorganizational interaction. However, the business page information model of the existing SNSs is not enough flexible to allow the definition of the field specific attributes that collectively characterize such nonmanufacturing organizations.

\section{Privacy Concerns and Issues of Data Transparency}

Privacy and data transparency are an important concern of business organizations, particularly the incepting organizations who experience higher levels of business competition with each other. Such organizations are always a bit reluctant to disclose their detailed technical information on open platforms fearing that it might go into the hands of their competitors. Therefore, they need the appropriate methods to know who is included in the network and explicitly control with whom their information is being shared. On the contrary, the existing multilateral WBCTs such as SNSs and media sharing platforms which are a promising opportunity for the emergent organizations to discover other organizations suffer from various security and privacy exposures [49], such as the publication of specific information on the network to unintended recipients due to poorly understood defaults, or a lack of awareness regarding the consequences of simple and presumably private actions, accidental data release, intentional use of private data for marketing purposes by the service provider, and so on [28]. The poorly defined privacy and transparency measures of existing tools cut down the number of participating organizations as well as the amount of information that the participants share thereon. This in turn limits the potential of these tools in disseminating partnering information and assisting the organizations in screening and selecting the potential partners for their collaborative projects.

\section{CONCLUSION}

In this paper, a hierarchical classification of existing web-based collaboration services applicable in interorganizational settings has been presented followed by the discussion on their challenges and inadequacies in supporting the inter-organizational connectivity throughout the collaboration process. While there already exist several WBCTs offering varying kinds of collaboration support, they fall inadequate in facilitating the desired technological support for the IOC process because of the scarcity of support for the advanced stages of collaboration process, service diversity and segmentation, lack of support for interoperability, and lack of appropriate data transparency and privacy measures. This indicates the need for designing and developing the dedicated platforms that support the organizations in attaining the higher levels of IOC throughout the process possibly integrating the information and interaction services offered by the existing solutions. Increasingly, such dedicated platforms 
could also be oriented around a specific business sector in order to incorporate the dedicated functionalities of the respective domain, and maintain the privacy, transparency, and relevancy of shared information. The domain specific IOC platforms would not only facilitate but also nurture the practices of web-based IOC by encouraging the organizations to extend their existing collaborations being undertaken in physical settings to the virtual environment, and establish new collaborations across the geographic borders.

This paper constitutes an early step towards such a paradigm shift from general community platforms to the dedicated platforms for inter-organizational connectivity. Further work on the investigation of the general and field specific requirements of such platforms still needs to be done before that such platforms can be developed and applied in the practice.

\section{ACKNOWLEDGEMENT}

Atia Bano Memon wishes to thank the University of Sindh and Higher Education Commission of Pakistan for sponsoring her doctoral studies at the University of Leipzig, Germany.

\section{REFERENCES}

[1] Abuhashesh, M. Y. 2014. Integration of Social Media in Businesses. International Journal of Business and Social Science 5, 8.

[2] Aghaei, S., Nematbakhsh, M. A., and Farsani, H. K. 2012. Evolution of the world wide web: From WEB 1.0 TO WEB 4.0. International Journal of Web \& Semantic Technology 3, 1, 1 .

[3] Alotaibi, M. B. 2013. E-commerce adoption in Saudi Arabia: an assessment of international, regional and domestic web presence. International Journal of Information Technology and Computer Science (IJITCS) $5,2,42$.

[4] Avram, G. At the crossroads of knowledge management and social software. In Academic Conferences Ltd.

[5] Batterink, M. H., Wubben, E. F. M., Klerkx, L., and Omta, S. W. 2010. Orchestrating innovation networks: The case of innovation brokers in the agri-food sector. Entrepreneurship and Regional Development 22, 1, 4776.

[6] Benbya, H., Passiante, G., and Belbaly, N. A. 2004. Corporate portal: a tool for knowledge management synchronization. International Journal of Information Management 24, 3, 201-220.

[7] boyd, d. m. and Ellison, N. B. 2007. Social Network Sites: Definition, History, and Scholarship. Journal of Computer-Mediated Communication 13, 1, 210-230.

[8] Caliñgo, A. R., Sison, A. M., and Tanguilig III, B. T. 2016. Prediction Model of the Stock Market Index Using Twitter Sentiment Analysis. International Journal of Information Technology and Computer Science (IJITCS) $8,10,11-21$.

[9] Frey, B. B., Lohmeier, J. H., Lee, S. W., and Tollefson, N. 2006. Measuring collaboration among grant partners. American journal of evaluation 27, 3, 383-392.

[10] Fuchs, C., Hofkirchner, W., Schafranek, M., Raffl, C., Sandoval, M., and Bichler, R. 2010. Theoretical foundations of the web: cognition, communication, and co-operation. Towards an understanding of Web 1.0, 2.0,
3.0. Future Internet 2, 1, 41-59.

[11] Gajda, R. 2004. Utilizing collaboration theory to evaluate strategic alliances. American journal of evaluation 25, 1 , $65-77$.

[12] Getting, B. 2007. Basic Definitions: Web 1.0, Web. 2.0, Web 3.0. http://www.practicalecommerce.com/articles/ 464-Basic-Definitions-Web-1-0-Web-2-0-Web-3-0. Accessed 29 March 2016.

[13] Haakanson, L., Caessens, P., and MacAulay, S. 2011. InnovationXchange: A case study in innovation intermediation. Innovation 13, 2, 261-274.

[14] Hagedoorn, J. 1993. Understanding the rationale of strategic technology partnering: inter-organizational modes of cooperation and sectoral differences. Strategic management journal 14, 5, 371-385.

[15] Hagedoorn, J. 2002. Inter-firm R\&D partnerships: an overview of major trends and patterns since 1960. Research policy 31, 4, 477-492.

[16] Hamel, G. 1991. Competition for competence and interpartner learning within international strategic alliances. Strategic management journal 12, S1, 83-103.

[17] Hargadon, A. and Sutton, R. I. 1997. Technology brokering and innovation in a product development firm. Administrative science quarterly, 716-749.

[18] Hevner, A. R., March, S. T., Park, J., and Ram, S. 2004. Design science in information systems research. MIS quarterly 28, 1, 75-105.

[19] Hogue, T. 1994. Community Based Collaboration: Community Wellness Multiplied. http://www.uvm.edu/ extension/community/nnco/collab/wellness.html. Accessed 13 April 2015.

[20] Itahriouan, Z., Abtoy, A., El Kadiri, K. E., and Aknin, N. 2012. Validated CMS: Towards new generation of web content management systems on Web 2.0. International Journal of Information Technology and Computer Science (IJITCS) 4, 12, 40 .

[21] Jefferson III, Carl E and Traughber, S. 2012. Social Media in Business. How Social Media Can Help Small Businesses and Non-Profit Organizations, 2-3.

[22] Jørgensen, F. and Ulhøi, J. P. 2010. Enhancing innovation capacity in SMEs through early network relationships. Creativity and innovation management 19, 4, 397-404.

[23] Kamel Boulos, Maged N and Wheeler, S. 2007. The emerging Web 2.0 social software: an enabling suite of sociable technologies in health and health care education 1 . Health Information \& Libraries Journal 24, 1, 2-23.

[24] Kane, K., Robinson-Combre, J., and Berge, Z. L. 2010. Tapping into social networking: Collaborating enhances both knowledge management and e-learning. Vine 40, 1, 62-70.

[25] Kaplan, A. M. and Haenlein, M. 2010. Users of the world, unite! The challenges and opportunities of Social Media. Business horizons 53, 1, 59-68.

[26] Li, J., Li, Q., Ginjala, A., and Zaman, N. 2014. eSMS-a Semantics-assisted Emergency Information System Based on Social Media. International Journal of Information Technology and Computer Science (IJITCS) 6, 08, 18-24.

[27] Lin, K.-Y. and Lu, H.-P. 2011. Why people use social networking sites: An empirical study integrating network externalities and motivation theory. Computers in human behavior 27, 3, 1152-1161.

[28] Lucas, M. M. and Borisov, N. 2008. Flybynight: mitigating the privacy risks of social networking. In Proceedings of the 7th ACM workshop on Privacy in the electronic society, 1-8.

[29] Malki, Z. 2015. Twitter as a Social Network in Academic Environments for Exchanging Information Taibah 
University: A Case Study. International Journal of Information Technology and Computer Science (IJITCS) 7, 10, 15 .

[30] Matthews, T., Whittaker, S., Moran, T., and Yuen, S. 2011. Collaboration personas: A new approach to designing workplace collaboration tools. In Proceedings of the SIGCHI Conference on Human Factors in Computing Systems, 2247-2256.

[31] Memon, A. B. and Meyer, K. 2015. CoDiT: An Integrated Business Partner Discovery Tool over SNSs. In Working Conference on Virtual Enterprises, 631-638.

[32] Meyer, K. and Thieme, M. 2010. Activating the Innovation Potential of SME: The Bottom-Up-Approach. In ISSS/BPSC, 3-16.

[33] Murugesan, S. 2007. Understanding Web 2.0. IT professional 9, 4, 34-41.

[34] O'reilly, T. 2007. What is Web 2.0: Design patterns and business models for the next generation of software. Communications \& strategies, 1, 17.

[35] Patel, K. 2013. Incremental Journey for World Wide Web: Introduced with Web 1.0 to Recent Web 5.0-A Survey Paper. International Journal of Advanced Research in Computer Science and Software Engineering 3, 10, 410 417.

[36] Peffers, K., Tuunanen, T., Rothenberger, M. A., and Chatterjee, S. 2007. A design science research methodology for information systems research. Journal of management information systems 24, 3, 45-77.

[37] Peterson, N. L. 1991. Interagency collaboration under part $\mathrm{H}$ the key to comprehensive, multidisciplinary, coordinated infant/toddler intervention services. Journal of Early Intervention 15, 1, 89-105.

[38] Porter, C. E. 2004. A typology of virtual communities: A multi-disciplinary foundation for future research. Journal of Computer-Mediated Communication 10, 1, 0.

[39] Powell, W. W., Koput, K. W., and Smith-Doerr, L. 1996. Interorganizational collaboration and the locus of innovation: Networks of learning in biotechnology. Administrative science quarterly, 116-145.

[40] Qureshi, S., Liu, M., and Vogel, D. 2006. The effects of electronic collaboration in distributed project management. Group decision and negotiation 15, 1, 5575.

[41] Razmerita, L., Kirchner, K., and Sudzina, F. 2009. Personal knowledge management: The role of Web 2.0 tools for managing knowledge at individual and organisational levels. Online information review 33, 6 , 1021-1039.

[42] Sawhney, M., Verona, G., and Prandelli, E. 2005. Collaborating to create: The Internet as a platform for customer engagement in product innovation. Journal of interactive marketing 19, 4, 4-17.

[43] Scott, J. E. 1998. Organizational knowledge and the intranet. Decision Support Systems 23, 1, 3-17.

[44] Simon, H. A. 1996. The sciences of the artificial 136. MIT press.

[45] Smedlund, A. 2006. The roles of intermediaries in a regional knowledge system. Journal of Intellectual Capital 7, 2, 204-220.

[46] Stelzner, M. A. 2014. Social Media Marketing Industry Report. How marketers are using social media to grow their businesses, Social Media Examiner. https:// www.socialmediaexaminer.com/

SocialMediaMarketingIndustryReport2014.pdf. Accessed 2 March 2017.

[47] Stelzner, M. A. 2015. Social Media Marketing Industry Report. How marketers are using social media to grow their businesses, Social Media Examiner. https:// www.socialmediaexaminer.com/

SocialMediaMarketingIndustryReport2015.pdf. Accessed 2 March 2017.

[48] Stelzner, M. A. 2016. Social Media Marketing Industry Report. How marketers are using social media to grow their businesses, Social Media Examiner. https:// www.socialmediaexaminer.com/wp-content/uploads/ 2016/05/SocialMediaMarketingIndustryReport2016.pdf. Accessed 2 March 2017.

[49] Strufe, T. 2009. Safebook: A privacy-preserving online social network leveraging on real-life trust. IEEE Communications Magazine, 95.

[50] Tess, P. A. 2013. The role of social media in higher education classes (real and virtual) - A literature review. Computers in human behavior 29, 5, A60 - A68.

[51] Thieme, M. and Meyer, K. 2011. Innovation through collaboration: a case-study based strategy to connect research institutions and enterprises. In Annual (SRII) Global Conference, SRII, 622-629.

[52] Turban, E., Liang, T.-P., and Wu, S. P. J. 2011. A framework for adopting collaboration 2.0 tools for virtual group decision making. Group decision and negotiation 20, 2, 137-154

[53] Venable, J., Pries-Heje, J., and Baskerville, R. 2012. A comprehensive framework for evaluation in design science research. In International Conference on Design Science Research in Information Systems, 423-438.

[54] Wagner, C. 2004. Wiki: A technology for conversational knowledge management and group collaboration. The Communications of the Association for Information Systems 13, 1, 58.

[55] Woodland, R. H. and Hutton, M. S. 2012. Evaluating Organizational Collaborations: Suggested Entry Points and Strategies. American journal of evaluation 33, 3, 366-383.

[56] Xiang, Z. and Gretzel, U. 2010. Role of social media in online travel information search. Tourism management 31 , $2,179-188$

\section{Authors' Profiles}

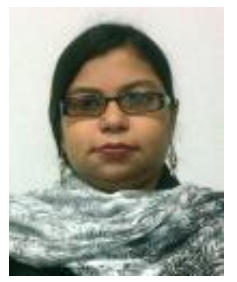

Atia Bano Memon is a Lecturer in Department of Computer Science at the University of Sindh, Pakistan and currently pursuing her $\mathrm{PhD}$ studies in Business Information Systems at the University of Leipzig, Germany with a foreign $\mathrm{PhD}$ scholarship from Higher Education Commission of Pakistan. She earned her degree of Master in Information Technology with distinction from University of Sindh in 2007. Her research interests include IT-supported service innovation, collaborative innovation, online innovation and collaboration platforms, and social media integration for business applications.

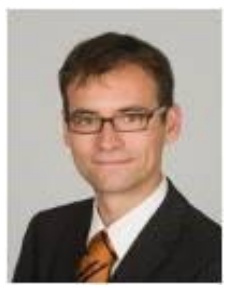

Dr. Kyrill Meyer is the CEO R\&D and the head of the Service Science and Technology research group at the Institute of Applied Informatics (InfAI) at the University of Leipzig, Germany. He earned his degree of $\mathrm{PhD}$ in Computer Science after studying and working at the W.C.S.C.C. in Ohio/USA, the University 
of Leipzig/Germany and the University of Maryland/USA. He was awarded with $\mathrm{PhD}$ degree in 2009 with a best young researcher award by the German Federal Ministry of Education and Research. His research interests include IT-based Service Engineering, Service Management and Service Science as well as IT-supported Innovation and Knowledge Management.

How to cite this paper: Atia Bano Memon, Kyrill Meyer, "Why We Need Dedicated Web-based Collaboration Platforms for Inter-organizational Connectivity? A Research Synthesis", International Journal of Information Technology and Computer Science(IJITCS), Vol.9, No.11, pp.1-11, 2017. DOI: 10.5815/ijitcs.2017.11.01 